\title{
Prototipagem rápida no desenvolvimento de produtos: construção do protótipo de um adaptador para escrita
}

Rapid prototyping in product design: prototyping a writing adaptive equipment

\section{Mayanne Camara Serra}

Universidade Estadual do Maranhão

may.produto@gmail.com

André Leonardo Demaison Medeiros Maia

Pontifícia Universidade Católica do Rio de Janeiro

demaison@gmail.com

Patrício Moreira de Araujo Filho

Universidade Estadual Paulista - UNESP

pmaraujof@yahoo.com.br

M

Eduardo Mendonça Pinheiro

Universidade Estadual do Maranhão

eduardomp1979@gmail.com

\section{PROJËTICA}

\section{COMO CITAR ESTE ARTIGO:}

SERRA, M. A.; MAIA, L. D. M.; ARAÚJO FILHO, P. M.; PINHEIRO, E. M. Prototipagem rápida no desenvolvimento de produtos: construção de protótipo de um adaptador para escrita. Projética, Londrina, v. 11, n. 1, p 108-133, 2020.

DOI: $10.5433 / 2236-2207.2020 v 11 n 1 p 108$

Submissão: 03-02-2017

Aceite: 23-05-2019

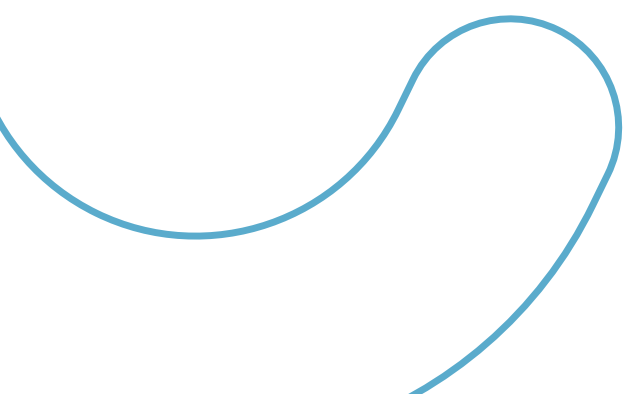


RESUMO: Neste artigo, esclarece-se sobre a tecnologia Fused Filament Fabrication e são descritas, com auxílio de fotografias, a concepção e construção do protótipo de um adaptador de escrita para crianças com restrições motoras nas mãos. Houve o mesmo processo de modelagem em CAD e impressão 3D com uma máquina Ultimaker 2 para dois modelos, em que o segundo resultou da correção de não conformidades do primeiro. Ademais, realça-se que o adaptador resultou da integração entre as áreas de Terapia Ocupacional, Design e Engenharia do Produto.

Palavras-chave: Desenvolvimento de produtos. Fused filament fabrication. Prototipagem. Protótipos.

ABSTRACT: In this paper, we describe the Fused Filament Fabrication technology and present, with pictures, the designing and assembling of a writing adaptive equipment prototype for children with motor limitations in the hands. The same process - CAD modeling and 3D printing using an Ultimaker 2 machine - was applied for two models, being that the second resulted from the corrections and improvements of the first one. In addition, it is emphasized that the adaptive tool resulted from the integration between the Occupational Therapy, Design and Product Engineering areas.

Keywords: Product design. Fused filament fabrication. Protoyping. Prototypes.

\section{INTRODUÇÃO}

Um dos meios de uma organização obter diferencial competitivo pode estar no próprio produto ou serviço, através de preço baixo, alta qualidade, design inovador, entre outros fatores. Com isso, quanto aos produtos, revela-se a constante necessidade de investir no desenvolvimento de novos produtos ou na 
Projética, Londrina, v.11, n.1, p. 108-133, abril 2020

melhoria dos já existentes, desta forma se aplica também o conceito de inovação exposto em Silva et al. (2015).

Vale apresentar o processo de desenvolvimento de novos produtos como meio de sanar necessidades que cada vez mais surgem, requerendo invenções ou adaptações em prol do atendimento de consumidores em geral. Contudo, importa destacar que existe uma parcela da população que não tem efetivamente suas necessidades atendidas por determinados produtos existentes no mercado, ou até mesmo pela ausência de produtos para as suas necessidades especiais. Essa parcela é formada por pessoas que possuem alguma restrição física, sensorial ou mental.

Dessa forma, a alta demanda e a baixa disponibilidade de produtos projetados com âmago na acessibilidade tendem a encarecê-los. Isto sinaliza para um campo de mercado que pode ser explorado, desde que existam mais investimentos em desenvolvimento de novos produtos, abrangendo também as formas de viabilização da sua produção.

No contexto do desenvolvimento de produtos, em vários momentos do projeto, pode ser requerida a materialização da ideia até então somente representada de forma bidimensional por meio de esboços e desenhos. Essa materialização pode ser obtida com a construção de protótipos e modelos tridimensionais, devendo-se destacar a Prototipagem Rápida (PR) como um dos processos de construção de protótipos através da impressão 3D.

Pela Prototipagem Rápida, peças modeladas em ambiente virtual são impressas tridimensional-mecanicamente, seguindo o princípio construtivo por material em camadas. No mercado existem vários tipos de processos de PR, que podem ser baseados em líquidos, pós ou materiais sólidos. Entre esses processos, mais especificamente entre os baseados em sólidos, há a chamada tecnologia 
Fused Filament Fabrication (FFF), ou por tradução para o português, "fabricação por filamento fundido", em que filamentos de material plástico sólido passam por processo de fusão e posterior extrusão, formando as camadas de material que constroem a peça de acordo com o modelado.

A partir do contextualizado, apresenta-se que este artigo tem em seu propósito a abordagem sobre a PR no âmbito do desenvolvimento de produtos, sendo que o objetivo principal é descrever a construção do protótipo de um adaptador para escrita voltado para crianças com restrições motoras nas mãos. Vale mencionar que a criação do adaptador resultou de um Trabalho de Conclusão de Curso no âmbito da Engenharia de Produção e possui registro de patente no Instituto Nacional da Propriedade Industrial (INPI).

\section{PROTÓTIPOS NO PROCESSO DE DESENVOLVIMENTO DE PRODUTOS}

O Processo de Desenvolvimento de Produtos (PDP) se encontra na interface entre a empresa e o mercado com clientes cujo poder de barganha tem se elevado significativamente. Nessa perspectiva, os investimentos em desenvolvimento de produtos são necessários sempre que percebido que os consumidores estão em busca de produtos que atendam suas necessidades. Assim, as empresas buscam atendê-las por meio de novos projetos, melhoria dos já existentes, criação de novas linhas, revisões e ou reposicionamentos no mercado com a redução de custos (OLIVEIRA NETTO; TAVARES, 2006; ROZENFELD et al., 2007).

É válido destacar que no início de um projeto se deve alcançar o objetivo de ter um novo produto que seja competitivo no mercado, mas ao mesmo tempo viável e possível de manufaturar com os recursos e capacidades operacionais da organização. No entanto, deve-se frisar que, no desenvolvimento de produtos, muitas boas ideias podem não alcançar o sucesso se não existir um projeto estruturado ou simplesmente se não houver o conhecimento do processo 
Projética, Londrina, v.11, n.1, p. 108-133, abril 2020

tecnológico para a tangibilidade do produto em projeto (OLIVEIRA NETTO; TAVARES, 2006; ROTONDARO et al., 2010).

O modelo de referência mais facilmente encontrado na literatura para o PDP em Engenharia do Produto envolve, basicamente, três macrofases, que são: pré-desenvolvimento, referindo-se ao Planejamento Estratégico, em que é incluída a determinação do portfólio de produtos; desenvolvimento, que se subdivide nas fases de planejamento do projeto, projeto informacional, projeto conceitual, projeto detalhado, preparação da produção e lançamento do produto; e pósdesenvolvimento, que consiste no acompanhamento do produto e nas atividades de sua descontinuação de acordo com seu ciclo de vida (BATALHA, 2008; CALEGARI; OLIVEIRA; LENZ, 2014; ROZENFELD et al., 2006).

Tem sido notória a necessidade de contínuas alterações visando a melhoria do PDP pelas empresas, visto que o mercado se apresenta com a concorrência cada vez mais acirrada e há a exigência de produtos cujos processos de fabricação tendem a ser complexos. Essas alterações buscam a maior celeridade no processo de desenvolvimento de novos produtos, em que há a utilização de softwares viabilizadores de projetos, análises, simulações e otimizações no contexto de processos de fabricação (VOLPATO, 2007).

$\mathrm{Na}$ fase do desenvolvimento do PDP, antes da etapa de elaboração do detalhamento da documentação técnica no desenvolvimento de produtos, é necessário que existam desenhos ou representações do produto por meio de ferramentas computacionais, como forma de realizar o panorama da inovação. No projeto de produtos, há momentos em que é revelada a necessidade da criação de protótipos para que o produto seja testado devido aos riscos de iniciar uma produção completa e para aumentar a qualidade do produto ao facilitar a comunicação interna na equipe do PDP (ROTONDARO et al., 2010; SLACK; JOHNSTON; CHAMBERS, 2015; VOLPATO, 2007). 
No contexto do desenvolvimento de produtos, em vários momentos do projeto, pode ser requerida a materialização da ideia até então somente representada de forma bidimensional por meio de esboços e desenhos. Essa materialização pode ser obtida com a construção de protótipos e modelos tridimensionais, devendo-se destacar a Prototipagem Rápida (PR) como um dos processos de construção de protótipos através da impressão 3D.

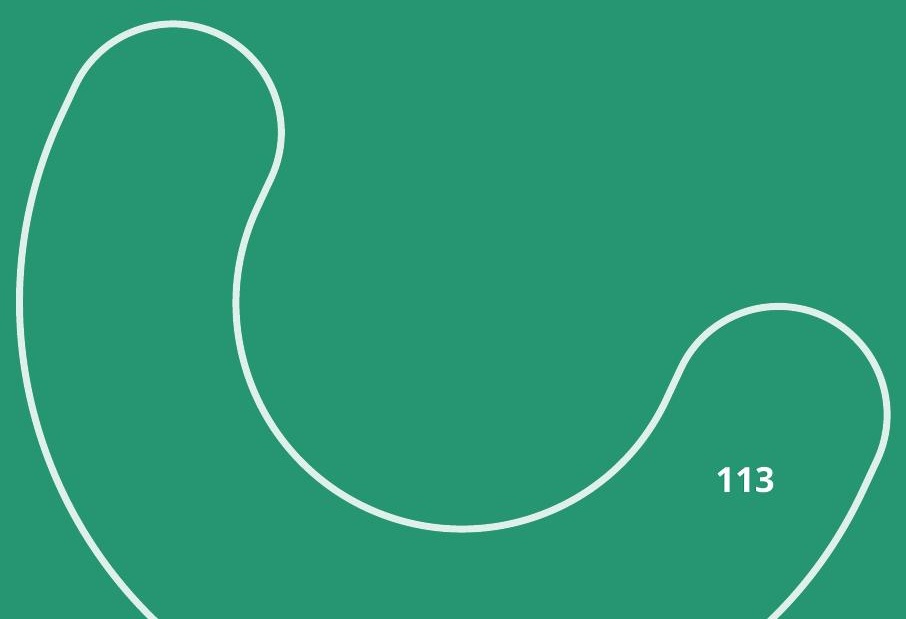


Projética, Londrina, v.11, n.1, p. 108-133, abril 2020

\section{A PROTOTIPAGEM RÁPIDA}

Os processos de fabricação mecânicos, pelos quais protótipos podem ser feitos, advêm de fusão, remoção, conformação e adição de material. Para complementar esse conjunto de processos, no final da década de 80 foi desenvolvido um processo que envolve a adição de material, mas que ocorre em camadas planas, facilitando a automatização, dispensando moldes e minimizando a atuação de operadores: a Prototipagem Rápida (PR) ou também chamada de Manufatura Aditiva (ALLEN; TRASK, 2015; VOLPATO, 2007).

Os pontos positivos da PR decorrem da produção de peças tridimensionais a partir de informações geométricas de sistemas CAD. A princípio, a PR se limitava à materialização de esboços do produto nas fases iniciais do PDP. Contudo, diante da necessidade de testar também o desempenho de produtos, em especial quanto às suas funções e qualidade, a aplicação da PR foi ampliada e passou a ser abrangida pelas áreas de Engenharia, Planejamento e análise, Manufatura e Manipulação de ferramentas (VOLPATO, 2007).

Existem várias técnicas e processos de Prototipagem Rápida, podendo ser identificadas no mercado mais de vinte sistemas. Embora as técnicas sejam diferentes, a metodologia da PR pode ser resumida nas seguintes etapas (VOLPATO, 2007):

1- Obtenção do modelo 3D a partir de sistemas CAD (modelagem);

2- Conversão de modelo em CAD para a extensão "STL" (StereoLithography adequação da superfície da peça em uma malha de triângulos);

3- Checagem da conversão;

4- Criação e localização de suportes quando necessário;

5- Definição da orientação de construção (vertical ou horizontal);

6- Fatiamento e ajuste de parâmetros para construção em camadas; 
7- Execução da máquina (processamento/construção/fabricação);

8- Pós-Processamento (retirada de suportes, limpeza, pós-cura, acabamento, etc.).

É comum encontrar, didaticamente, a classificação dos processos de PR de acordo com o estado inicial da matéria-prima utilizada; isto é, em "Baseado em Líquido", "Baseado em Sólido" e "Baseado em Pó". Para esses conjuntos, há os seguintes principais exemplos (VOLPATO, 2007):

a) Baseado em Líquido: StereoLitography (SL);

b) Baseado em Sólido: Fused Filament Fabrication (FFF), Fused Deposition Modeling (FDM) e Laminate Object Manufacturing (LOM);

c) Baseado em Pó: Selective Laser Sintering (SLS) e 3 Dimensional Printing (3DP).

Das tecnologias elencadas, enfatiza-se que este estudo se delimita à FFF, visto que foi a utilizada na construção do protótipo a ser descrito posteriormente. Neste aspecto, informa-se que a definição da FFF se baseia na identificação prévia da possibilidade de o processo gerar protótipos muito próximos ou equivalentes ao produto final (se este último também possuir termoplásticos como matériaprima ou material de propriedades semelhante). Para maior compreensão dessa tecnologia, há as abordagens das próximas linhas.

\section{FUSED FILAMENT FABRICATION}

A Fused Filament Fabrication (FFF) se originou com o projeto RepRap desenvolvendo uma tecnologia semelhante à FDM, porém de código aberto. Desta forma, foi obtido um método de impressão 3D baseado na extrusão térmica de material termoplástico, que é depositado por meio de um cabeçote móvel, formando camadas de material de acordo com o esquematizado pela Figura 1 (ALLEN; TRASK, 2015; LANGNAU, 2012). 
Projética, Londrina, v.11, n.1, p. 108-133, abril 2020

Figura 1 - Esquema do princípio de funcionamento da tecnologia FFF

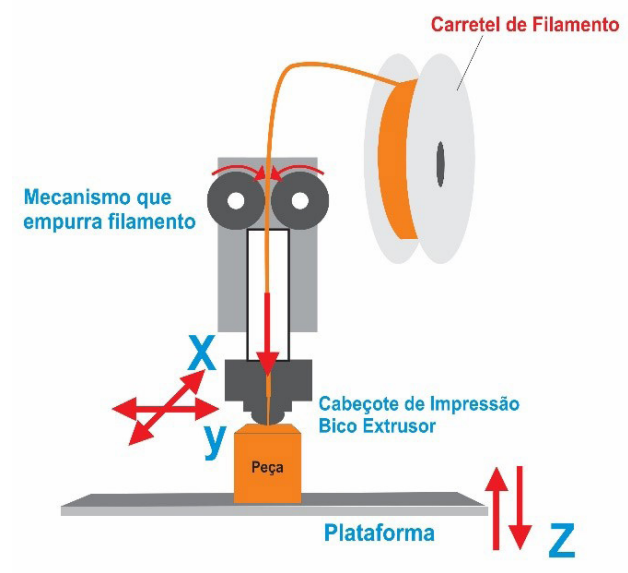

Fonte: Adaptado de 3D Printing for Beginners (2014).

A matéria-prima da FFF, em geral, são os filamentos termoplásticos de ABS (Acronitila Butadileno Estireno) e PLA (Ácido Poliático), que são de relativo baixo custo e fácil aquisição no mercado. O ABS é derivado de petróleo e tem como principais pontos positivos a solidificação rápida e a resistência a impactos, porém como pontos negativos há o fato de não ser biodegradável, a tendência ao empenamento e a possibilidade de emitir fumaça durante o processo da FFF. Já o PLA é derivado de amido de milho e, por isso, seu ponto forte é o fato de ser um bioplástico, mas seu ponto fraco está na baixa resistência da peça pronta ao calor (BLUEMAX, 2013; MALINAUSKAS et al., 2014; SANTANA et al., 2018).

Vale deixar em relevo que na tecnologia FFF, na sua forma atual e tradicional, é permitido ao usuário o controle da maioria dos parâmetros do processo e ela ainda é encontrada na maior parte das máquinas de prototipagem do mercado atual. Ademais, deve-se complementar que, devido ao princípio de funcionamento da tecnologia FFF, podem ser empregados filamentos de outros tipos de materiais, como os polímeros PA (Poliamida), PP (polipropileno), HDPE (polietileno de alta densidade), dentre outros (MOZA et al., 2015; SANTOS et al., 2018). 


\section{MATERIAIS E MÉTODOS}

Após etapa prévia de revisão de literatura para subsidiar o desenvolvimento do trabalho prático, idealizou-se um adaptador para auxílio de escrita por crianças com restrições motoras nas mãos, com denominação de "adaptador para escrita" ou, para este artigo, a denominação simplificada de "adaptador". De antemão, deve-se mencionar que os equipamentos e materiais utilizados no estudo foram cedidos pelo curso de Design da Universidade Federal do Maranhão.

A concepção do adaptador ocorreu a partir da busca de algo tangível que pudesse ser considerado inovador e, ao mesmo tempo, simples para a aplicação da prototipagem, sendo o contexto escolhido a Tecnologia Assistiva, inserida na área de Terapia Ocupacional. É importante ressaltar que na Tecnologia Assistiva é buscado elevar a autonomia de pessoas com mobilidade reduzida ou restrições motoras através do desenvolvimento de adaptações para a realização de tarefas cotidianas, como escrever, por exemplo.

Para o protótipo em abordagem, baseou-se em uma postagem em um site de reabilitação de Leite (2014), que trata de uma adaptação para a escrita com um prendedor de roupas para auxiliar a preensão de objetos de escrever por pessoas com disfunções motoras nas mãos. Desta forma, o adaptador desenvolvido se baseou no modelo do prendedor de roupas da Figura 2:

A etapa de modelagem do adaptador contou com contribuições de profissionais de Terapia Ocupacional, que analisaram os desenhos iniciais e sinalizaram sugestões a partir de suas experiências. Nesta análise, houve a elaboração de esboços baseados no modelo de prendedor de roupas escolhido para o trabalho, pelo qual foi buscada a eliminação de partes da configuração física que não seriam necessárias para a função do adaptador, visto que foi pensado também na economia de material, processos e tempos. 
Figura 2 - Modelo de prendedor de roupas utilizado
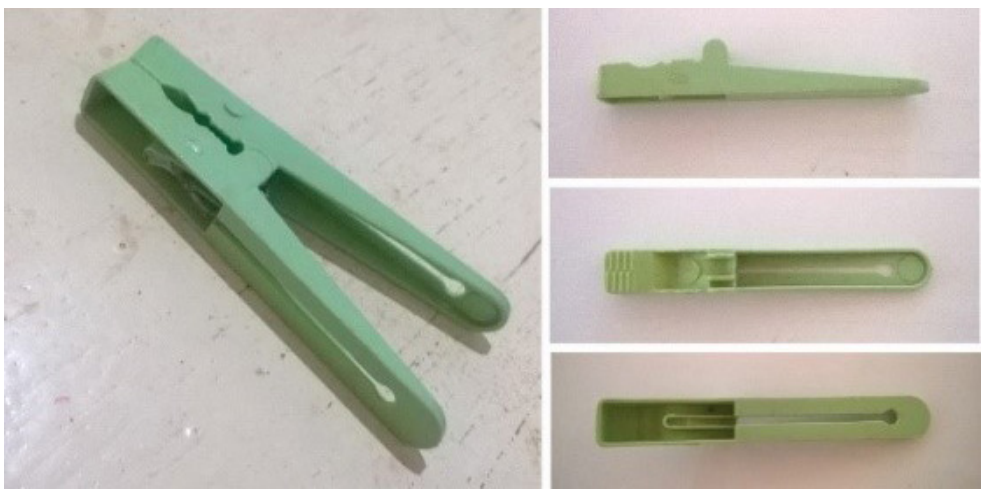

Fonte: Acervo dos autores

A etapa de modelagem do adaptador contou com contribuições de profissionais de Terapia Ocupacional, que analisaram os desenhos iniciais e sinalizaram sugestões a partir de suas experiências. Nesta análise, houve a elaboração de esboços baseados no modelo de prendedor de roupas escolhido para o trabalho, pelo qual foi buscada a eliminação de partes da configuração física que não seriam necessárias para a função do adaptador, visto que foi pensado também na economia de material, processos e tempos.

$\mathrm{Na}$ etapa de construção do protótipo foram utilizados dois modelos, que foram formalizados pelo software AutoCAD e, em seguida, convertidos para a extensão "STL". Essa conversão se deve à necessidade de leitura pelo software CURA, que é utilizado pela impressora 3D Ultimaker 2, empregada neste estudo. Para a realização da prototipagem, foram cedidos como matéria-prima filamentos de plástico ABS, que resultam em peças mais resistentes em relação ao PLA.

Em descrição sucinta, foram realizados dois processos de impressão referentes aos dois modelos, visto que as não-conformidades apresentadas na primeira peça construída direcionaram para a alteração do modelo inicial com base 
nos parâmetros da impressora utilizada, bem como devido a outras dificuldades em relação à forma do adaptador, resultando no segundo modelo. Os processos de impressão 3D, com a Fused Filament Fabrication realizados para construção do protótipo do adaptador, foram registrados por meio de fotografias e vídeos, compondo informações para este artigo.

O equipamento de impressão 3D utilizado no trabalho se trata da Ultimaker 2, que é da fabricante Ultimaker (cujos fundadores participaram do Projeto RepRap). Pela Figura 3 é possível visualizar componentes importantes para o funcionamento da máquina utilizada e para a compreensão do processo:

Figura 3 - Visão dianteira (1: placa móvel de vidro; 2: entrada para cartão SD; 3: visor; 4: botão de navegação; 5: plataforma móvel de construção; 6: cabeçote de impressão), visão superior (7: Tubo-guia de filamento; 8: cabo do cabeçote de impressão; 9: carretel de filamento; 10: fonte) e visão traseira (11: alimentador de material)
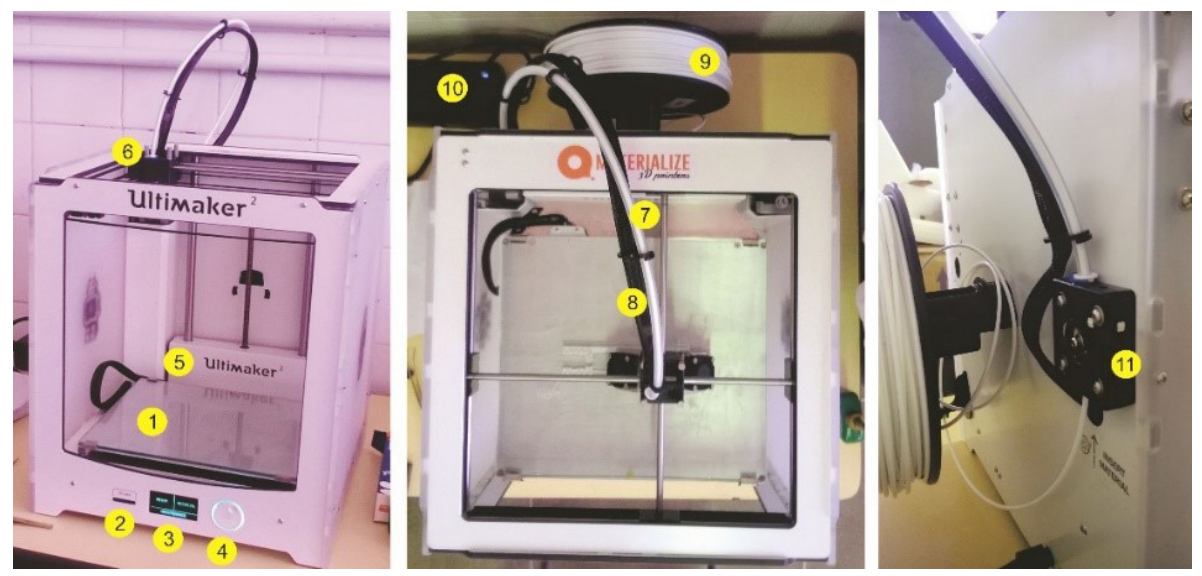

Fonte: Acervo dos autores

Conforme informações do fabricante, a máquina pesa em torno de 11 $\mathrm{kg}$; suas dimensões são $35,7 \mathrm{~cm} \times 34,2 \mathrm{~cm} \times 38,8 \mathrm{~cm}$ e pode imprimir uma peça 
Projética, Londrina, v.11, n.1, p. 108-133, abril 2020

com dimensões até o limite de $23 \mathrm{~cm}$ x 22,5 cm x 20,5 cm. Um aspecto positivo é a não necessidade de se conectar a um computador para operar, pois a leitura do arquivo pode ocorrer diretamente de um cartão de memória e funciona de modo adequado em temperatura ambiente. O bico de extrusão, localizado no cabeçote de impressão (Figura 4), pode alcançar temperatura de 180 a $260^{\circ} \mathrm{C}$; possui 04 $\mathrm{mm}$ de diâmetro e, devido a isso, alguns casos de peças complexas com partes cujas dimensões são menores que $04 \mathrm{~mm}$ podem não apresentar um resultado de construção preciso quanto ao modelado.

Figura 4 - Cabeçote de impressão 1: visão superior; 1.1: localização do cabeçote de impressão em posição não-operante; 2: visão dianteira; 3: visão inferior; 3.1: localização do bico de extrusão
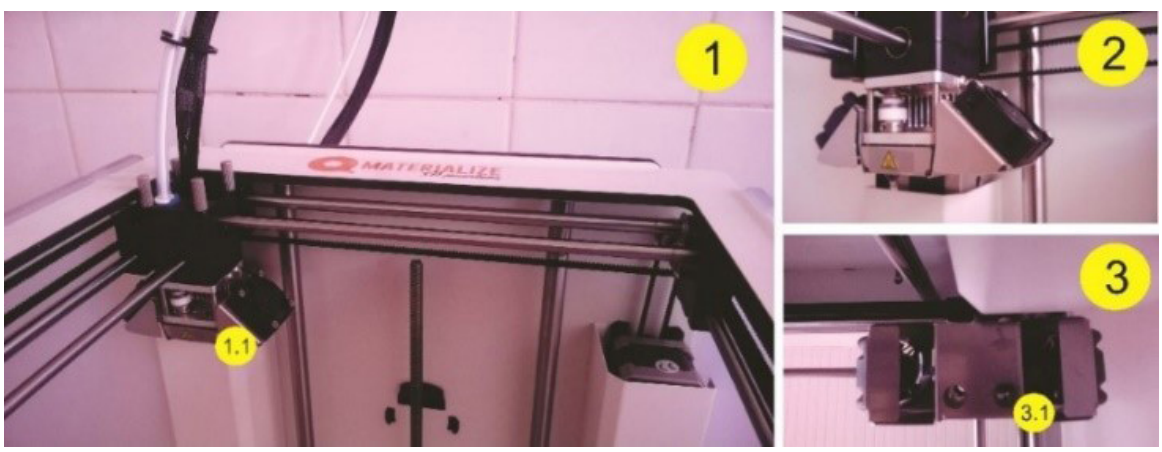

Fonte: Acervo dos autores

As matérias-primas que podem ser consumidas pela Ultimaker 2 utilizada são apenas filamentos de PLA ou ABS com diâmetro de 2,85 mm e podem ser coloridos. A máquina imprime em velocidade de 30 a $300 \mathrm{~mm} / \mathrm{s}$, podendo resultar camadas de material com precisão de $02 \mathrm{~mm}$ sob determinados parâmetros de configurações avançadas e, também, dependendo do formato da peça a ser construída. 


\section{RESULTADOS E DISCUSSÕES}

A partir do formato do prendedor de roupas escolhido, foi desenvolvido um modelo inicial para o adaptador buscando a simplificação da forma, aumento de dimensões e o acréscimo de uma pulseira de feltro (que não foi confeccionada pela impressão 3D) para melhor suporte do adaptador à mão do usuário. Esse modelo não envolveu possíveis restrições de precisão da máquina, mas foi buscado o aproveitamento da mesma conexão metálica do prendedor de roupas utilizado, porém com a minimização dos nichos laterais para essa conexão que, no caso, ficou formada por duas subpeças "macho" e "fêmea".

Devido à necessidade de existir uma espécie de pulseira para prender o adaptador à mão do usuário, aproveitou-se a ideia dos cortes nas pegas do prendedor de roupas do estudo, como se observa nos desenhos em CAD na Figura 5:

Figura 5 - Modelagem 3D virtual com o AutoCad do primeiro modelo do adaptador

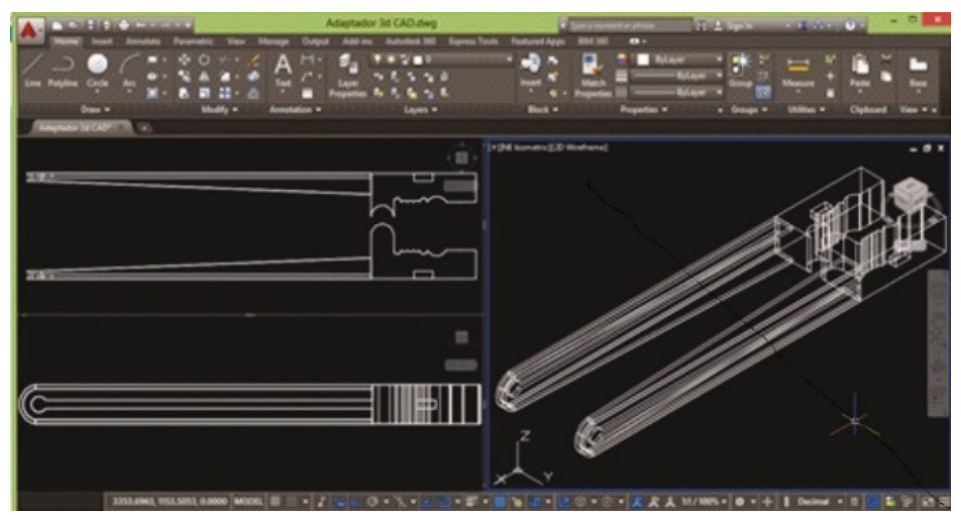

Fonte: Acervo dos autores

Após modelagem em CAD na direção horizontal, o desenho foi convertido para a extensão "STL" com o software CURA, que permite à impressora utilizada ler e imprimir tridimensionalmente os desenhos. No CURA, a peça foi fatiada, 
Projética, Londrina, v.11, n.1, p. 108-133, abril 2020

automaticamente, em noventa e oito camadas em um parâmetro de fatiamento triangular, em que a peça não seria oca e nem totalmente preenchida (Figura 6). Assim sendo, o software informou que a peça final iria consumir $0,81 \mathrm{~m}$ de filamento em 06 gramas e com tempo de impressão estimado de uma hora e quarenta minutos.

Figura 6 - Modelo sob o modo Layers do CURA e na $84^{\mathrm{a}}$ camada do fatiamento

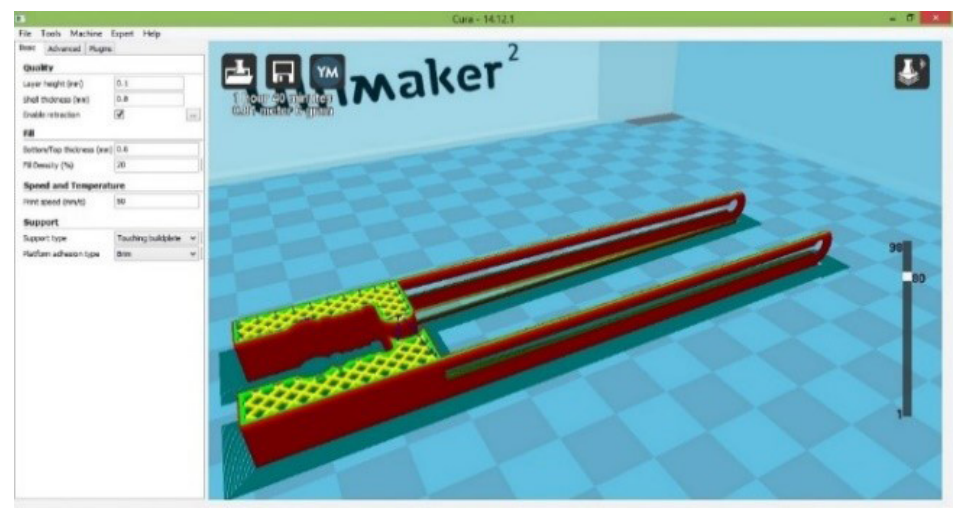

Fonte: Acervo dos autores

Os passos iniciais para a impressão 3D foram o aguardo do aquecimento automático do cabeçote de extrusão da máquina e o acréscimo de cola de PVC na placa de extrusão para evitar que a peça se desprenda da placa de vidro e seja arrastada com o deslocamento do cabeçote durante o processo de construção da peça.

O processo de impressão 3D começa com a placa de vidro subindo automaticamente até próximo do cabeçote, que expele uma pequena quantidade de filamento derretido que não é usado para construir a peça. A primeira camada a ser construída é preenchida em sua totalidade para, em seguida, ser iniciada a impressão sob os parâmetros de fatiamento, como se nota pela Figura 7: 
Figura 7 - Início do processo de impressão 3D, primeiras camadas totalmente preenchidas e início da impressão sob parâmetros de fatiamento
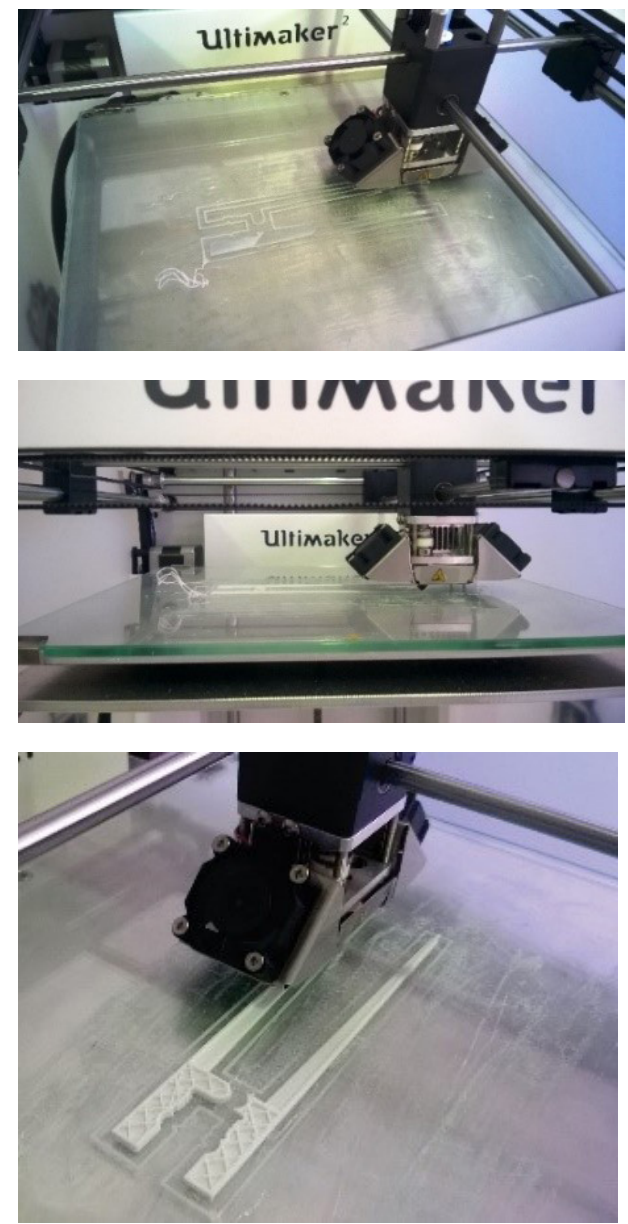

Fonte: Acervo dos autores

Quando o processo estava em torno da metade do seu tempo de conclusão, foi notado que as camadas da peça começaram a se soltar nas paredes mais finas enquanto o cabeçote se deslocava (Figura 8). Todavia, o processo não foi interrompido e se finalizou com o preenchimento total das últimas camadas da peça. 
Projética, Londrina, v.11, n.1, p. 108-133, abril 2020

Figura 8 - Quebras e camadas se soltando durante a impressão 3D do primeiro modelo

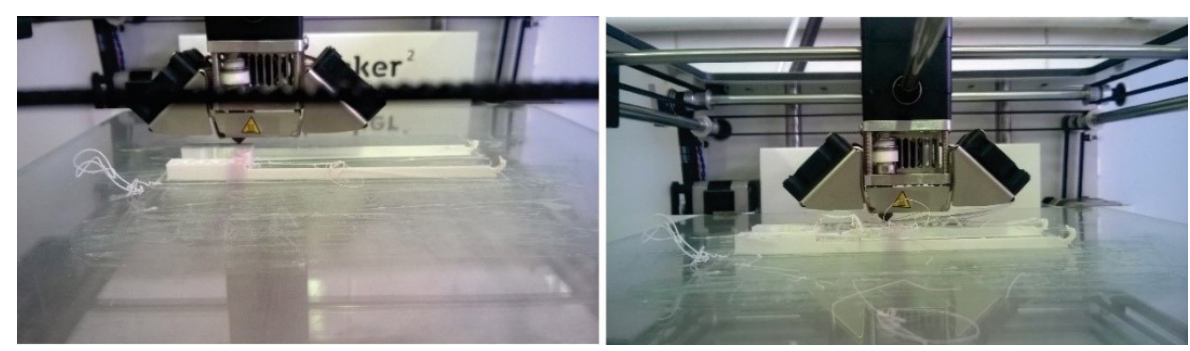

Fonte: Acervo dos autores

Figura 9 - Primeiro modelo impresso
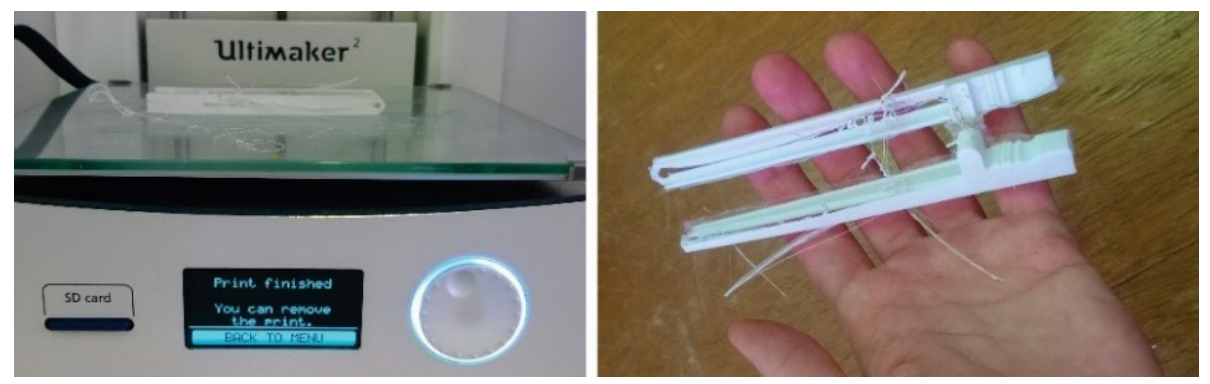

Fonte: Acervo dos autores

Após a confecção do adaptador, notou-se que as dimensões da peça estavam de acordo com o modelo, no entanto, não-conformidades foram identificadas e não puderam ser corrigidas. Destas não-conformidades, estavam as camadas soltas nas partes mais finas da peça, que se quebraram, e a não identificação de elementos pequenos, como ranhuras e nichos em decorrência da 
inferioridade em relação aos parâmetros de precisão do bico de extrusão, que são de $04 \mathrm{~mm}$. Além disso, a peça resultante ficou com cantos "vivos" e, possivelmente, cortantes em suas partes retas, configurando risco para o usuário, como observado na Figura 10:

Figura 10 - Não-conformidades do primeiro modelo impresso

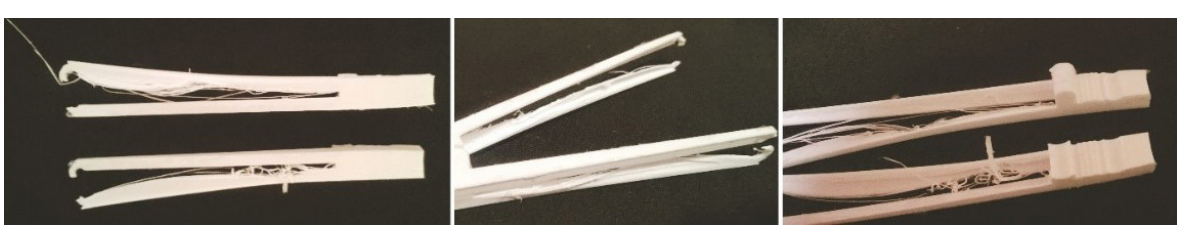

Fonte: Acervo dos autores

Buscando sanar as não-conformidades citadas, houve a modelagem de um segundo formato de adaptador, com as seguintes alterações: aumento de espessuras, redução do espaço das pegas para passar a pulseira de feltro; substituição de ranhuras por ondulações suaves; arredondamento de cantos retos; e redução das dimensões de comprimento e largura para melhor distribuição de esforços, formando o modelo notado pela Figura 11:

Figura 11 - Modelagem em CAD do segundo modelo para o adaptador

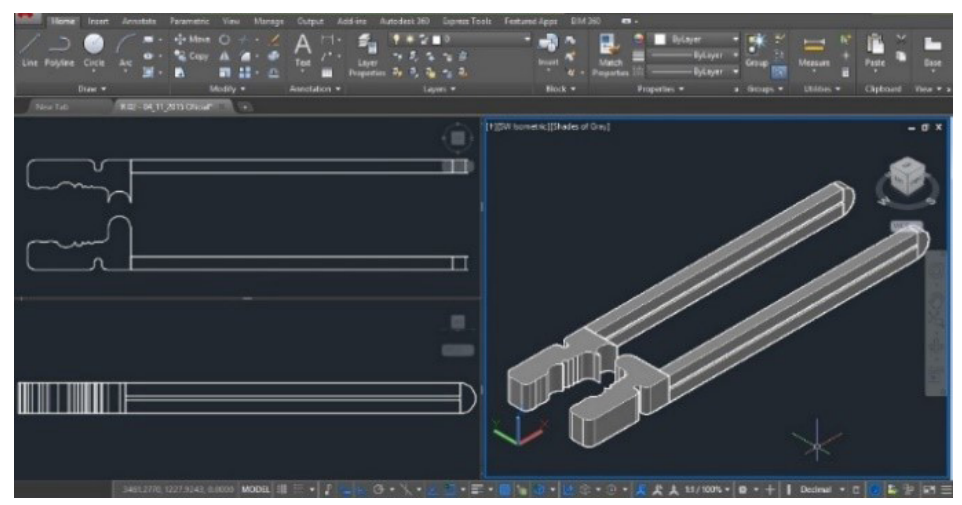

Fonte: Acervo dos autores 
Projética, Londrina, v.11, n.1, p. 108-133, abril 2020

Após conversão do arquivo em CAD para a extensão "STL", o CURA indicou o fatiamento da peça em setenta e oito camadas sob as configurações automáticas (Figura 12), além de estimativas de consumo de material em 0,91m, $07 \mathrm{~g}$ e com tempo de impressão aproximado de uma hora e cinquenta e oito minutos.

Figura 12 - Segundo modelo no software CURA

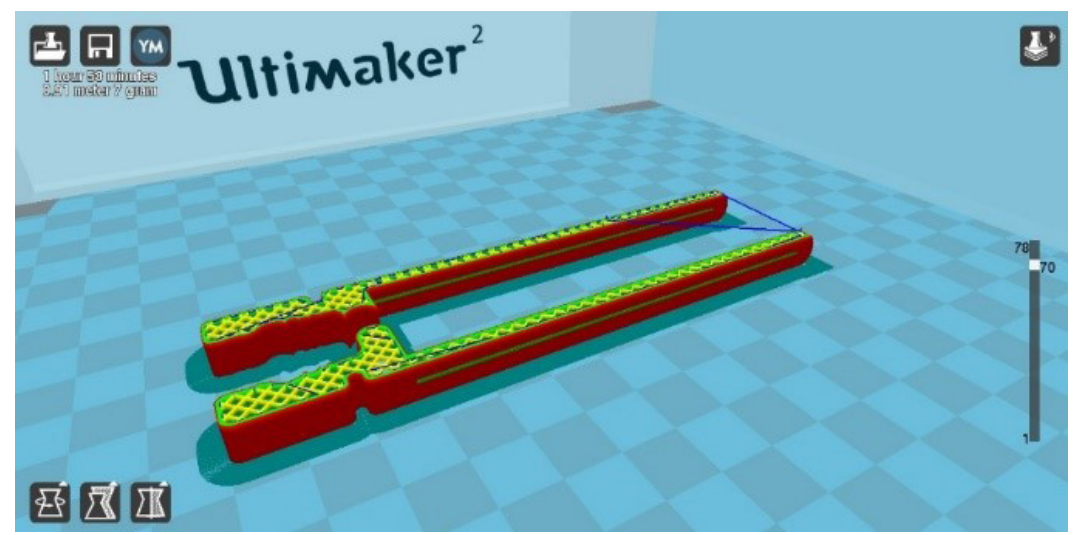

Fonte: Acervo dos autores

Foram repetidos os passos iniciais do processo de impressão do primeiro modelo para este segundo, sendo que o processo está demonstrado de forma simplificada através da Figura 13:

Finalizado o processo de impressão do segundo modelo, notou-se que não ocorreram as não-conformidades do primeiro formato. Em contrapartida, notouse que os formatos dos elementos vazados ficaram visivelmente mais estreitos que o modelado em CAD e as subpeças ficaram com formato levemente curvo. Com isso, acredita-se que a quantidade de cola de PVC utilizada não foi suficiente para manter fixas as subpeças enquanto eram impressas, sendo estas levantadas durante deslocamento do cabeçote de impressão. 
Figura 13 - Início da impressão 3D com primeiras camadas totalmente preenchidas; em torno da metade do processo e sob parâmetros de fatiamento e finalização do processo com preenchimento total de últimas camadas
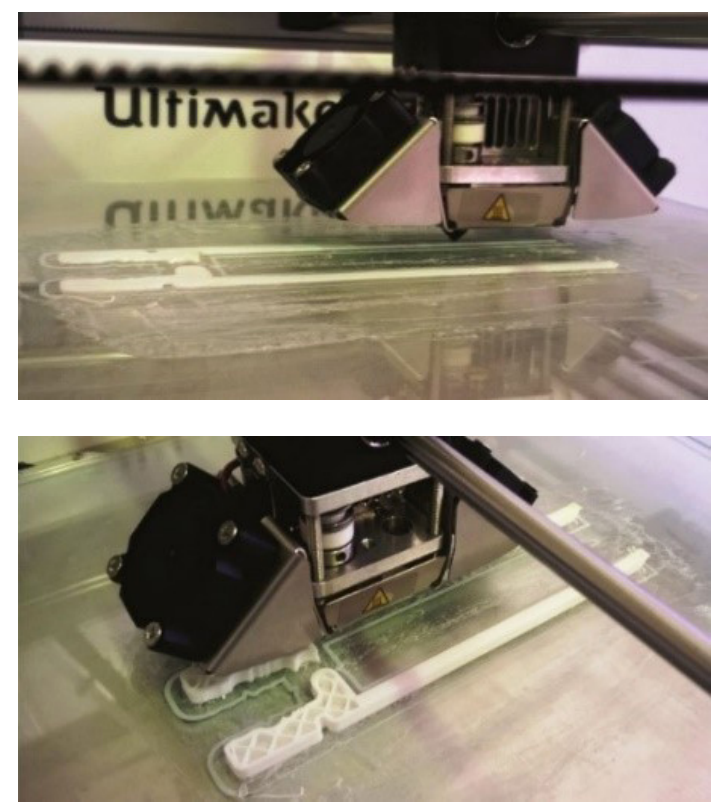

Adicionalmente, é válido reiterar dos estudos de Santana et al. (2018) que peças impressas tridimensionalmente com filamentos de ABS já possuem uma tendência prévia ao empenamento, sendo esta mais uma causa para o resultado deste protótipo. 
Projética, Londrina, v.11, n.1, p. 108-133, abril 2020

Figura 14 - Não-conformidades do segundo modelo
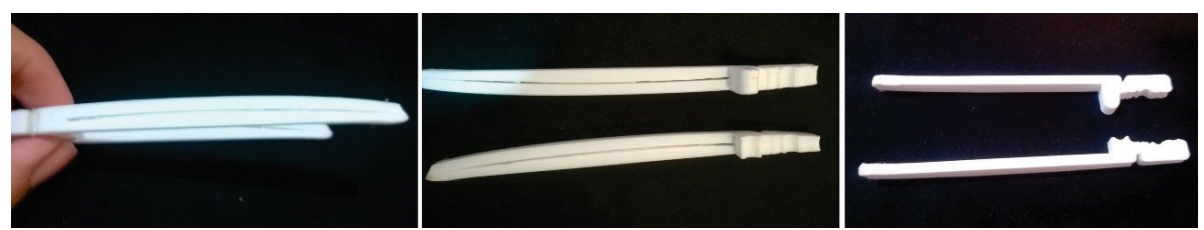

Fonte: Acervo dos autores

Apesar de a peça obtida não ter sido fiel ao modelado, decidiu-se dar continuidade à construção do protótipo, conforme o segundo modelo, para a realização de testes de funcionalidade do adaptador. Então, as subpeças foram unidas por um fio de silicone e foi acrescentada a pulseira de feltro no protótipo do adaptador desenvolvido para teste com usuário, como demonstrado na Figura 15:

Figura 15 - Teste do protótipo concluído quanto à sua funcionalidade por uma usuária pré-adolescente
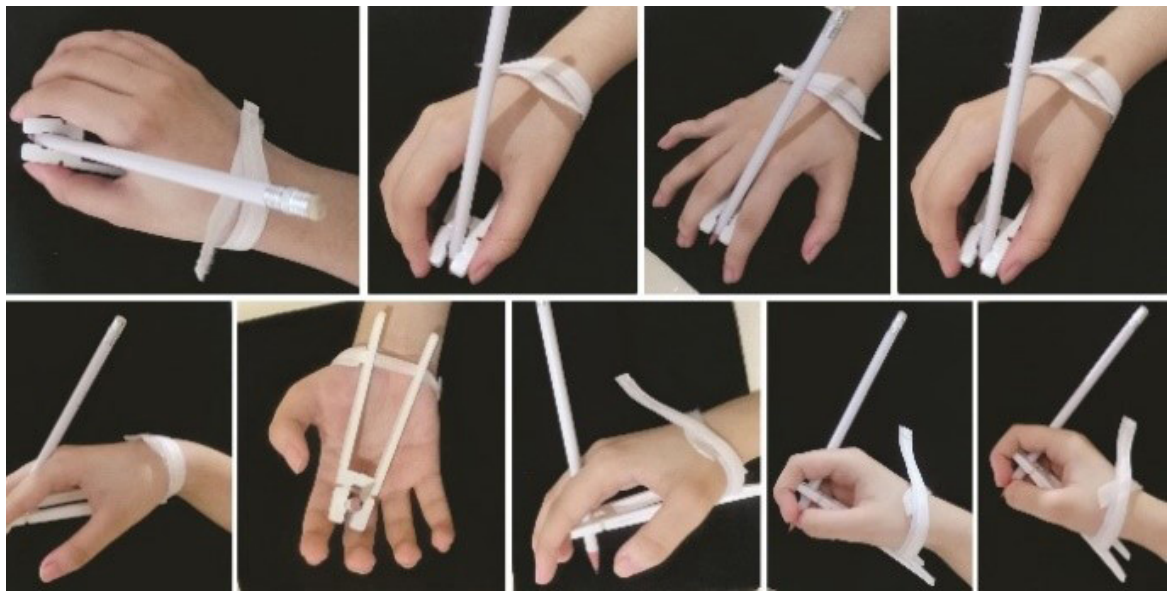

Fonte: Acervo dos autores

O resultado do protótipo do segundo modelo sinalizou que o adaptador, muito provavelmente, seja funcional apenas para crianças ou jovens préadolescentes, pois ficou pequeno e leve para sustentar objetos de escrita grandes. 
Nesse aspecto, acredita-se que o nível de desempenho do protótipo do adaptador resultante é semelhante ao do uso de prendedores de roupas como explicado por Leite (2014).

Deve-se acrescentar que as mãos de pessoas adultas, em especial as de homens, tendem a ter dimensões mais elevadas. Por isso, é requerido um suporte bastante efetivo ao escrever, o que pode não ser atendido pelo modelo de adaptador desenvolvido neste estudo.

A partir do descrito e considerando as referidas peças construídas como primeiros protótipos de um adaptador para escrita destinado a crianças com restrições motoras nas mãos, que ainda pode passar por outros testes e melhorias no seu desenvolvimento, sintetiza-se que o processo de prototipagem pela tecnologia FFF se desenvolveu adequadamente. Isto porque houve a transformação de uma determinada quantidade de filamento plástico de $A B S$ em um objeto tridimensional, conforme várias especificações desejadas, e com funcionalidade relevante.

\section{CONCLUSÕES}

Embora o protótipo construído ainda não possa ser considerado como versão final, pois requer melhorias, ele ainda pode ser utilizado em estudos posteriores para ser aperfeiçoado, abrangendo testes e estudos ergonômicos para criação de modelos com alterações de dimensões, por exemplo. Deve-se acrescentar que, a partir do trabalho desenvolvido, demonstra-se a possibilidade do processo de Prototipagem Rápida ser usado, também, como um processo de manufatura, desde que o produto tenha propriedades semelhantes ao do protótipo. Contudo, fica sugerida para estudos futuros a análise de viabilidade atinente à produção industrial desse adaptador por meio da tecnologia FFF. 
Projética, Londrina, v.11, n.1, p. 108-133, abril 2020

Pela automação e relativa baixa complexidade do processo, notadas durante a construção do protótipo do adaptador descrito, compreende-se que a utilização de tecnologias de Prototipagem Rápida pode promover o desenvolvimento de produtos de forma "enxuta". Isso se reflete da dispensa de muitos materiais e de grande quantidade mão de obra, uma vez que apenas uma pessoa é suficiente para operar a máquina durante a construção de protótipos, como ocorreu durante o desenvolvimento do adaptador abordado neste artigo.

Ademais, por esse estudo houve a integração prática entre as áreas de Engenharia do Produto, de Design e de Terapia ocupacional. Diante disso, mostrase de grande valia a integração dessas áreas no desenvolvimento de produtos voltados para pessoas com necessidades especiais diversas. Com isso, realça-se como de inestimável importância a disseminação de trabalhos nesse contexto para a redução de desafios quanto à inclusão social e ao aumento da independência daqueles que possuem alguma restrição motora. 


\section{REFERÊNCIAS}

1. ALLEN, Robert J. A.; TRASK, Richard S. An experimental demonstration of effective curved layer fused filament fabrication utilising a parallel deposition robot. Additive Manufacturing, Wuhan, CN, v. 8, p. 78-87, Oct. 2015. Disponível em: http://www.sciencedirect.com/science/article/pii/S2214860415000445> Acesso em: 2 mar. 2016.

2. BATALHA, Mário (org.). Introdução à engenharia de produção. 6. ed. Rio de Janeiro: Elsevier, 2008.

3. BLUEMAX. What material should use for 3d printing? In: 3D PRINTING FOR BEGINNERS. 2013. Disponível em: http://3dprintingforbeginners.com/filamentprimer-2/. Acesso em: 5 ago. 2015.

4. CALEGARI, Eliana Paula; OLIVEIRA, Branca Freitas de; LENZ, Denise Maria. O desenvolvimento de produtos a partir de novos materiais: aplicação de biocompósitos no design de produtos. Projética: Revista Científica de Design, Londrina, v. 5, n. 2, p. 149-168, dez. 2014.

5. LANGNAU, Leslie. A closer look at extrusion-based 3D printers. 2012. Disponível em: http://www.makepartsfast.com/a-closer-look-at-extrusion-based-3d-printers/. Acesso em: 3 mar. 2016.

6. LEITE, Ana. Adaptação para escrever: use o prendedor de roupas! 2014. Disponível em http://www.reab.me/adaptacao-para-escrever-use-o-prendedor-de-roupas/. Acesso em: 2 jul. 2015. 
Projética, Londrina, v.11, n.1, p. 108-133, abril 2020

7. MALINAUSKAS, Mangirdas; REKŠTYTĖ, Sima; LUKOŠEVIČIUS, Laurynas; BUTKUS, Simas; BALČIŪNAS, Evaldas; PEČIUKAITYTĖ, Milda; BALTRIUKIENĖ, Daiva; BUKELSKIENĖ, Virginija; BUTKEVIČIUS, Arūnas; KUCEVIČIUS, Povilas; RUTKŪNAS, Vygandas; JUODKAZIS, Saulius. 3D microporous scaffolds manufactured via combination of fused filament fabrication and direct laser writing ablation. Micromachines, Los Angeles, CA, v. 5, n. 12, p. 839-858, 2014. Disponível em: http://www.mdpi.com/2072-666X/5/4/839/htm. Acesso: 5 ago. 2015.

8. MOZA, Z; KITSAKIS, K.; KECHAGIAS, J.; MASTORAKIS, N. Optimizing dimensional accuracy of fused filament fabrication using taguchi design. Recent Researches. Electrical and Computer Engineering, Fisciano SA, p. 110-114, 2015. Disponível em http://www.wseas.us/e-library/conferences/2015/Salerno/IMAS/IMAS-14.pdf. Acesso em: 5 ago. 2015.

9. OLIVEIRA NETTO, Alvim Antônio de; TAVARES, Wolmer Ricardo. Introdução à engenharia de produção: estrutura, organização, legislação. Florianópolis: Visual Books, 2006.

10. ROTONDARO, Roberto Gilioli; MIGUEL, Paulo A. Cauchick; GOMES, Leonardo Augusto de Vasconcelos. Projeto do produto e do processo. São Paulo: Atlas, 2010.

11. ROZENFELD, Henrique; FORCELLINI, Fernando Antônio; AMARAL, Daniel Capaldo; TOLEDO, José Carlos de. Gestão de desenvolvimento de produtos: uma referência para a melhoria do processo. São Paulo: Saraiva, 2006. 
12. SANTANA, Leonardo; ALVES, Jorge Lino; SABINO NETTO, Aurélio da Costa; MERLINI, Claudia. Estudo comparativo entre PETG e PLA para Impressão 3D através de caracterização térmica, química e mecânica. Matéria, Rio de Janeiro, v. 23, n. 4, 2018. Disponível em: http://www.scielo.br/pdf/rmat/v23n4/ 1517-7076-rmat-23-4-e12267.pdf. Acesso em: 2 maio 2019.

13. SANTOS, Luana Machado; ROCHA, Daniela Sousa Guedes Meirelles; CARNEIRO, Marcos Lajovic; LUZ, Marta Pereira. Tipos de polímeros utilizados como matéria prima no método de manufatura aditiva por FDM: uma abordagem conceitual. In: In: ENCONTRO NACIONAL DE ENGENHARIA DE PRODUCAO, 38., 2018, Maceió, AL. Anais [...]. Maceió: ABEPRO, 2018. Tema: A Engenharia de Produção e suas contribuições para o desenvolvimento do Brasil, p. 1-12. Disponível em: http://www.abepro.org.br/biblioteca/TN_STO_268_536_36043. pdf. Acesso em: 3 maio 2019.

14. SANTOS, Luana Machado; ROCHA, Daniela Sousa Guedes Meirelles; CARNEIRO, Marcos Lajovic; LUZ, Marta Pereira. Impactos da inovação incremental na produção de uma porta de abrir. Projética Revista Científica de Design, Londrina, v. 6, n. 2, p. 86-97. Edição Especial IDEMI 2015, outubro de 2015.

15. SLACK, Nigel; JOHNSTON, Robert; CHAMBERS, Stuart. Administração da produção. Tradução de Henrique Luiz Corrêa. 3. ed. São Paulo: Atlas, 2009.

16. 3D PRINTING FOR BEGINNERS. A comprehensive introduction to 3D printing technology. 2014. Disponível em: http://www.3dprintingforbeginners.com/ 3d-printing-technology/. Acesso em: 3 set. 2015.

17. VOLPATO, Neri (ed.). Prototipagem rápida: tecnologia e aplicações. São Paulo: Blücher, 2007.

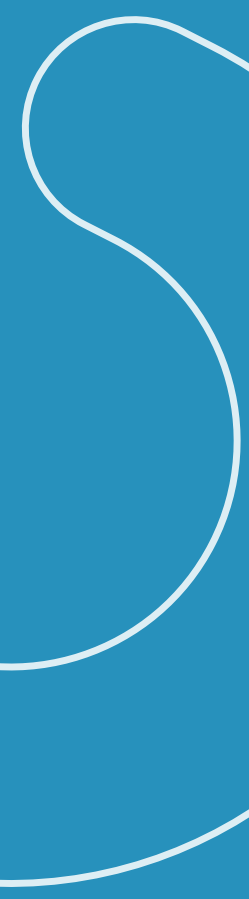

